


\title{
El sujeto enunciativo y sus espacios en algunos poemas de Francisco Hernández
}

\author{
Alejandro Palma Castro \\ Benemérita Universidad Autónoma de Puebla
}

Resumen:

En este artículo se desarrolla un análisis del sujeto enunciativo en algunos poemas de Francisco Hernández para mostrar la importancia, pero también urgencia, de profundizar en los estudios de enunciación en el discurso poético. A partir de la poética de Hernández, particularmente sugerente en lo que respecta a la apropiación de personalidades o máscaras, propongo una metodología y tipología más adecuadas para extender las posibilidades de su interpretación y lectura desde los espacios que se perciben en el poema a partir de la consideración del sujeto enunciativo, según algunos de los estudios críticos que existen a la fecha.

Palabras clave: Francisco Hernández, poesía mexicana del siglo $\mathrm{XX}$, sujeto enunciativo de la lírica, espacio y poesía.

\section{Abstract}

This article analyzes the subject of enunciation in some of Francisco Hernández's poems. This study lets me demonstrate the relevancy of a more structured criticism of what is call "enunciation studies" in poetry. Hernández's use of different personalities or masks in his poetry 
allows me to propose an adequate methodological and typological process of analysis in order to obtain a richer interpretation of his poetry from the point of view of the subject of the enunciation.

Keywords: Francisco Hernández, Mexican poetry 20th century, Subject of enunciation, Space and poetry.

Z n el ámbito de la poesía mexicana que se lee poco, se le hace Umenos crítica y, todavía peor, apenas y se la menciona en los programas de estudios universitarios de literatura, Francisco Hernández (1946) representa el caso de un poeta de culto. Este prolífico escritor tiene la suerte, dado el contexto, de ser de los pocos poetas mexicanos contemporáneos realmente leído. Diré, por fijar algunos parangones que complementen mi idea, que Hernández hace las veces en México, con las debidas reservas y diferencias del caso, de Héctor Viel Temperley en la década de los ochenta en la poesía argentina, o del español Leopoldo María Panero y su caterva de fieles lectores que lo han sostenido. En comparación con ambos personajes, Francisco Hernández también es un fenómeno de la década de los ochenta de la literatura mexicana. Palabras y nombres como fantasmas, Schumann, música, Scardanelli, griega o amor, tienen un significado especial para aquellos quienes han leído sus poemas, volviéndose cómplices de un secreto sobre los delirios de la poesía.

Esta maravilla que despierta Hernández en sus lectores se debe, en parte, a la creación de un personaje sostenido en su obra poética casi desde sus comienzos. Instancia que corresponde a lo que en la teoría de la poesía se ha dado en llamar el sujeto enunciativo de la lírica (Hamburger, 1995). En este trabajo me dedicaré a mostrar, mediante algunos análisis a la poesía de Hernández, quién y cómo es tal enunciador que fascina a aquellos que lo reconocen. La poesía de Francisco Hernández me parece un caso apropiado 
para distinguir ciertos espacios donde se manifiesta un sujeto lírico que le ha brindado particularidad a su obra poética. Considero además que el uso adecuado de una terminología en la teoría de la poesía puede brindar nuevos aportes y extender las posibilidades de lectura de una obra tan sugerente como la de Hernández. En particular, propongo modificar "máscara poética”, término que me parece más apropiado para lecturas impresionistas, por "sujeto enunciativo"; finalmente, no se trata de quién hable, sino de lo que traiga a cuenta cuando hable, una máscara nos limita espacialmente, en cambio un sujeto abre, tras de sí, una concepción del mundo reflejada en espacios específicos.

Comenzaré, entonces, marcando el desarrollo del concepto "sujeto enunciativo" en la lírica, el cual deriva de los primeros estudios de enunciación. La enunciación literaria ha sido un procedimiento estudiado de manera profunda apenas a mitad del siglo XX, a pesar de que ya Aristóteles introduce en su Arte poética una diferencia en el modo de imitar a partir de la enunciación: "con los mismos medios es posible imitar las mismas cosas unas veces narrándolas (ya convirtiéndose hasta cierto punto en otro como hace Homero), ya como uno mismo y sin cambiar, o bien presentando a todos los imitados como operantes y actuantes" (1974: 133). Desde entonces, una diferencia entre los géneros literarios ha sido el tipo de enunciador que emite el discurso. En la lírica, el modo de enunciar subjetivamente desde "uno mismo y sin cambiar" produce un espejismo que confunde al autor con el enunciador. Si bien ciertas épocas de la literatura han aprovechado esta circunstancia, parte de la poesía romántica por ejemplo, no parece ser el sentido común de la lírica y mucho menos de aquella escrita durante el siglo XX.

Emile Benveniste, en su obra Problemas de lingüistica general, propuso la figura discursiva de la enunciación como el acto individual de apropiación de la lengua (1966: 83), aquel al cual solamente se accede por medio de ciertas marcas que deja en su discur- 
so. Esto motivará un estudio más profundo por parte de Tzvetan Todorov, con un artículo seminal "Problèmes de l'énonciation", donde establece que: "la enunciación está siempre presente, de una manera o de otra, en el interior del enunciado; las diferentes formas de esta presencia así como los grados de su intensidad permiten establecer una tipología de discursos. Entramos aquí en el dominio del análisis del discurso, o de la lingüística textual, o si se prefiere llamar por su nombre antiguo, de la retórica" (1970: 8; la traducción es mía).

En este ámbito de restablecimiento de la retórica para el estudio del texto poético, la crítica comienza a estudiar la presencia enunciativa en la lírica apelando a lo que usualmente denominamos voz, personaje o sujeto. Pere Ballart, en El contorno del poema, propone que "leer el poema será tomar decisiones sobre la identidad del personaje que habla y sobre la situación en que lo hemos sorprendido inmerso, y sobre si aquél, por así decir, simplemente está pensando en voz alta, o bien dirige su discurso a algún otro personaje" (2005: 185). Este tipo de decisiones están enmarcadas, de acuerdo con Ballart, en distintas formas de dramatización, puesto que "la figura a la que aluden todos los "yoes" que haya en el texto no es el poeta en tanto que individuo empírico, inscrito en el registro civil, sino la persona poética — la persona, la máscara- que la voz del poema anima a construir" (2005: 188). Por lo tanto, esta voz constituirá una figura que podemos denominar, siguiendo a Käte Hamburger, el sujeto enunciativo lírico; ${ }^{1}$ este trabajo, escrito en alemán y traducido muchas décadas después al inglés, francés

${ }^{1}$ El término deriva de su trabajo de 1957, La lógica de la literatura, el cual, al publicarse en alemán, tuvo poca incidencia en el medio académico internacional. De hecho el libro circuló más al realizarse una segunda edición revisada en 1968. No obstante, la primera traducción al inglés de 1973 se realiza de la edición del 57, y la traducción francesa, de 1986, está basada en la 3a edición de 1977. Esto originó que el importante estudio sobre semiótica poética, encabezado por J. A. Greimas, no reparara en este importante antecedente y solamente 
y el español, resulta la piedra angular para, desde una perspectiva pragmática, entender las diferencias entre los géneros literarios a partir de las particularidades de su enunciación. De la lírica dirá:

la frontera que separa la enunciación lírica de otras formas de enunciación no viene establecida por la forma externa del poema, sino por la relación de la enunciación con el objeto [...] Pues el hecho de que la sensación que nos produce el poema sea la de campo vivencial de un sujeto enunciativo, y nada más que eso, resulta de que la enunciación de éste no apunta al polo del objeto sino que retrae éste a su propia esfera vivencial, y con ello, lo transforma (Hamburger, 1995: 195).

Derivado de un coloquio organizado en la década de los noventa, Dominique Rabaté presentó, en 1996, una compilación de trabajos sobre el sujeto lírico con el propósito de revalorar al "pariente pobre" del discurso crítico. Figures du sujet lyrique incluye a la lírica en el debate del sujeto enunciador, que años antes habían comenzado Bajtín, Genette y otros críticos, basándose particularmente en la narrativa. La noción central del trabajo asume al sujeto lírico como un punto de convergencia para la organización de la forma, el espacio de referencia, la tonalidad y un ethos escritural a partir de un contexto específico, sin por ello insinuar la unicidad en la poesía moderna. Partiendo del romanticismo, el conjunto de trabajos críticos de este libro fija términos y procedimientos más específicos, a lo que, por ejemplo, Ballart ha concebido aún vagamente como dramatis personae. Para Rabaté la enunciación lírica será un punto de encuentro de enunciados subjetivos que no pueden encontrar su unicidad y más bien, a partir del establecimiento de un nuevo lenguaje, se recrean como reflejo en el otro; por tanto, sostiene la tesis de que la enunciación lírica, como totalización de

se limitara a considerar que la enunciación era un enunciado de tipo especial "porque comporta otro enunciado en calidad de actante-objeto" (1976: 28). 
posturas enunciativas movedizas, es el espacio, el lugar de inscripción de un tipo de experiencias que logran configurarse cuando desbordan al sujeto; de experiencias que expresan una subjetividad que nada tiene que ver con un sujeto en el sentido de una instancia desde donde el poeta pudiera ejercer su dominio sobre ellas (1996: 68-69).

Paralelo a ese nuevo sentido del sujeto lírico y su función en el proceso de enunciación del poema lírico, se ha publicado otro libro colectivo, Teoría del poema: la enunciación lírica (1998), bajo la revisión de Fernando Cabo Aseguinolaza y Germán Gullón, donde se continúa indagando sobre el tema en la tradición de la poesía espańola, aunque, habrá que reconocerlo, no se atreven a aventurar una especificidad enunciativa de acuerdo con el discurso. Si acaso sobresalen en ello los primeros dos trabajos: "Entre Narciso y Filomena: Enunciación y lenguaje poético", de Cabo Aseguinolaza, y “¿Enunciación lírica?”, de José María Pozuelo Yvancos. De este último me gustaría destacar unas líneas, para efectos de mi interés investigativo, algo obvio pero sustantivo al referirnos al proceso de la enunciación en la lírica:

el lector vivencia en el poema una experiencia que convierte siempre en experiencia presente, y que por ello, como veremos luego le imbrica a él. El "ahora" de la poesía no remite al momento en que el poema fue escrito, sino al presente de su lectura. Igual valdría decir para los espacios recuperados, que son para la experiencia del lector imágenes de su propio mundo (Pozuelo, 1998: 42).

Por lo tanto, pensando tanto en la tipificación del sujeto lírico de Rabaté y esta cita anterior, se puede considerar que el espacio de enunciación del sujeto lírico no es unitario pero tampoco pertenece, como expresión subjetiva, a su emisor, sino, más bien, es un haz que entrecruza, o convoca, a la figura de la escritura y de la lectura. Este espacio, más que buscarse desde los rasgos sintácticos y se- 
mánticos que pueda configurar una entidad enunciativa, se deberá plantear desde una perspectiva espacio temporal de la enunciación a partir de la cual se reproduce una experiencia o, como menciona Pozuelo Yvancos, "una zona en la que el yo establece la experiencia del tiempo no como un tema o asunto sino como la dominante de toda su construcción” (1998: 46).

Aun sin precisar metodológicamente o siquiera convenir una terminología adecuada para aclarar el proceso singular de la enunciación lírica, me parece que estos trabajos han adelantado sobremanera lo que parecía un evidente desfase en contraste con la narrativa o incluso el teatro. Es necesario comenzar a analizar puntualmente este proceso de enunciación en la poesía para determinar los alcances de lo que puede ser un distinto y enriquecedor modo de concebir el sentido en el poema. En este sentido propongo como caso de estudio algunos poemas de Francisco Hernández.

Al compilar la principal poesía veracruzana de los siglos XIX y XX, Esther Hernández Palacios y Ángel José Fernández caracterizan a la obra de Francisco Hernández de la siguiente manera:

Si bien comparte con Orlando Guillén y Carlos Isla el afán por lo eminentemente experimental en una primera instancia de su obra, luego encuentra, a partir de sus poemas aparecidos en Cuerpo disperso (1982), al decantar la suma de sus experiencias innovadoras de la forma poética, un tono personal, que a partir de entonces ha venido puliendo y sacando en claro (1992: 87).

En efecto, decía líneas antes que Hernández representa un fenómeno literario de los ochenta porque es en esa época, con los libros que publica, cuando llama la atención de algunos lectores, sobre todo cuando cierra la década con la aparición de De cómo Robert Schumann fue vencido por los demonios (1988). Este poemario, multiantologado y citado con frecuencia, será el texto definitivo para cultivar a varios asombrados lectores para quienes Schumann se 
convierte en un personaje memorable al cual, en ciertos momentos de lucidez, quizás podemos escuchar cantando lo siguiente:

\section{XIII}

La niña Clara camina por la playa en el límite justo de las olas.

El color de su piel toca la espuma.

El caracol aprende sus palabras.

La niña Clara camina por el bosque con agujas de pino entre los labios. Pasa un azul de plumas invisibles. Una pared de hiedra se levanta.

La niña Clara camina por la nieve con los ojos cerrados y las manos abiertas.

En sus dedos hay flores de Turingia.

En sus ojos tigres de Bengala² (28-29).

Al salir del embeleso de esta bella canción preguntaría: ¡y quién nos canta sobre la niña Clara?, ¿el poeta Hernández?, ¿Schumann aún resistiendo a los demonios?, ¿un cantor anónimo y anodino que me presta su voz? Pudiera contestar que quizás todos y ninguno a la vez. Para explicar, me remito a "Los signos de la brújula", poema publicado en el primer libro de Francisco Hernández, Gritar es cosa de mudos (1974). ${ }^{3}$ El texto abre con una dedicatoria a Ezra Pound que nos ayuda a interpretar los primeros dos versos: "Alguien le ha regalado una isla/ al viejo pastor de los ojos curtidos"

${ }^{2}$ Todas las citas a este poemario provienen de la $3^{\text {a }}$ edición de Moneda de tres caras (2013).

${ }^{3}$ Utilizo la versión del poema contenida en Antojo de trampa. Segunda antología personal (1999). 
(1999: 16). Se trata del entierro del poeta norteamericano en la isla que alberga el histórico cementerio de Venecia. Este par de marcas, una dedicatoria y los versos iniciales, nos instalan en el marco de una elegía. La voz del poema ha decidido distenderse en un espacio íntimo desde el cual se lamenta la muerte de Ezra Pound pero, a la vez, encuentra cierto consuelo de que haya sido en el mar, ya que nos dice: "La agonía frente al mar/ siempre es dichosa./ El tifón orienta los signos de la brújula" (1999: 16). Y tras una descripción que lleva el sentido de un consuelo, el sujeto lírico se dirige al poeta muerto y le pide "Sin embargo, sin miedo, sin tarea, has de cabalgar/ sobre los dioses militantes" (1999: 16) y así sigue anticipándole una misión de lucha para darle "una nueva,/ ruidosa/ ocupación/ a tu eco sin palabras" (1999: 16), pues le parece que el nombre de Ezra Pound "tañe por la tarde/ en oro brusco" (1999: 16). En esta última parte del poema, el sujeto lírico plantea la necesidad de una mejor comprensión del poeta, quien no ha sido valorado como se debiera. El espacio de la elegía se transforma paulatinamente en el de una increpación a la ceguera con la cual se ha leído a Pound. Los signos de la brújula, título del poema y parte de un verso, tienden a invitarnos a acceder al poeta imaginista sin los pesados prejuicios que pesaron por sus antecedentes históricos con el fascismo italiano.

En la actualidad parecerá casi imposible imaginar que se ponga en duda la valía de la obra de Ezra Pound, pero en el contexto de la década de los setenta del siglo pasado, aún en las vísperas de su muerte, el gran aparato crítico norteamericano no había olvidado del todo la alta traición cometida a la patria en los momentos de la Segunda Guerra Mundial. Este dato, que se muestra tan palpable en la enunciación del poema, pasaría desapercibido si nos obstináramos en sostener que el poema se presenta siempre en un aquí y ahora de la recepción. En este caso particular, el tiempo presente de nuestra lectura de "Los signos de la brújula" no es el mismo bajo 
el cual se presenta el esquema enunciativo del sujeto lírico, por ende aparecen dos instancias en el acto de la lectura del poema: el que lo ejecuta en el contexto de la reciente muerte de Ezra Pound y quien lo lee en cualquier otro momento.

Esta pieza de Hernández me permite demostrar que si no consideramos que en el texto poético existe un enunciador vinculado a un tiempo y espacio precisos, se corre el riesgo de desarticular su sentido. En el caso que me ocupa, de no comprender que el enunciador se encuentra instalado en el contexto de la casi inmediata muerte de Ezra Pound, donde aún varios sectores de la crítica eran prejuiciosos con su obra por su polémico pasado fascista, el poema no tendría un sentido completo y, sobre todo la última parte, podría parecer hermético. El lector del poema debe cobrar noción de que confluye en el tiempo y el espacio con un sujeto enunciativo específico.

Vuelvo entonces con la niña Clara. Decía que podíamos considerar que la voz de la canción eran tres instancias y ninguna a la vez. Pensemos en un sujeto lírico particular capaz de amalgamar, en un tiempo y espacio específicos (llamémosle locus de enunciación), a estas tres instancias. Un poeta llamado Francisco Hernández, a quien le ha seducido la música de Schumann y luego el conocimiento de su biografía, plantea de manera inicial lo siguiente:

Miro la música de Schumann como se ve un libro, una moneda o una lámpara.

Ocupa su lugar en la sala situándose, con movimientos felinos, entre el recuerdo de mi padre y el color de la alfombra. De pronto, pájaros muertos estrellan las ventanas.

Yo miro la música de Schumann 
y escribo este poema

que crece con la noche $(\mathrm{s} / \mathrm{p})$.

Éste sería propiamente el espacio, una sala que se vuelve música y recuerdos, y el tiempo, una noche que avanza, desde donde el sujeto lírico recreará la tragedia de Schumann cediendo a la locura; por ello, desde ese tiempo presente, apelará al músico alemán mediante el diálogo: "Hoy converso contigo, Robert Schumann, / te cuento de tu sombra en la pared rugosa/ y hago que mis hijos te oigan en sus sueños" (2013: I, 23). Así, el esquema deíctico del poema se realizará desde un yo hacia un tú, que será un Schumann vencido por las visiones demoníacas reconociéndose por medio de los versos. El poeta ha buscado cuidar la verosimilitud de su obra por medio del recurso del diálogo, dado que sería una cuestión propia de la fantasía, e incluso descuidada, poner en boca del mismo Schumann una vida que sus trastornos mentales le borraron.

La secciones en De cómo Robert Schumann fue vencido por los demonios alternan tiempos verbales para distinguir varias voces. En el presente aparece el poeta que escribirá la historia de Schumann desde su música, en pretérito y copretérito se narran los pasajes de la vida del músico, y también en presente aparecen las intervenciones de una voz que se permite presencializar, esto es evocar en un aquí y ahora con una profunda expresión lírica que se transmite al lector. Se trata del momento en el cual se muestra la poesía; como, por ejemplo, la sección VI que comienza con una letanía: "Para que salga el sol, música de Schumann. / Para destejer un tapiz, música de Schumann. / Para besar a mi mujer, música de Schumann” (2013: 25) y también, desde luego, la canción de la niña Clara.

El sujeto lírico, que tiene su locus de enunciación desde la propia música de Schumann en una noche donde emprende un diálogo vivo con el músico, transforma la experiencia en un acto para tranquilizar "al otro que en mí se desespera” (2013: I, 23). Entonces no es Schumann o Clara o el poeta Francisco Hernández, 
sino otro implacable, desasosegado — vale la pena aquí recordar un verso de Borges en "Borges y yo": "Al otro, a Borges, es a quien le ocurren las cosas" (1999: 22) —. El interés por la locura de Schumann y Hölderlin, los delirios de Trakl y la enigmática existencia de Charles B. Waite, representan una manera de despersonalizar a un sujeto sintiente para instalar en su lugar a otro, un enunciador, "la máscara", según se refiere comúnmente, quien cobra consciencia de la sensación sintiente para recrearla de manera artística. En el caso del libro De cómo Robert Schumann fue vencido por los demonios nos encontramos con un sujeto lírico que muestra tal proceso: del poeta, pasando por el personaje, para llegar a la máscara o personaje. José Ma. Espinasa lo explica de manera sencilla y clara:

El poeta (o el creador) vive en el texto como arquetipo, sin desprenderse de su condición de persona, así no es — no puede serni Schumann, ni Trakl, ni Hölderlin, pero tampoco Francisco Hernández, sino un yo que les pertenece a todos y que el lector modula para hacerlo suyo (2005: 75).

Este recurso es el que ha vuelto identificable y célebre la obra de Francisco Hernández, algo que guarda mucho parecido con el proyecto de heterónimos de Fernando Pessoa. Precisamente el poeta veracruzano también ha creado un heterónimo: Mardonio Sinta, un repentista cuya vida va de 1929 a 1990. Sus coplas han sido editadas por la UNAM, con un prefacio del mismo Hernández. La despersonalización del sujeto, de la cual hablaba líneas antes, no parece un recurso fortuito sino un proyecto de obra bien definido y establecido que se explica en términos similares a la propuesta del poeta portugués.

Este argumento, aunado a la interpretación de "Los signos de la brújula” que propuse al principio, me permite abrevar en la poesía y los poetas como uno de los principales tópicos de la poesía de Francisco Hernández. Se podrá pensar que esto no es distinto a 
otras poéticas contemporáneas, sobre todo de matiz coloquial, que autorefieren el proceso de creación literaria como elemento cotidiano, sin embargo (y aquí es donde se instituye parte del culto), Hernández ha creado un espacio particular a partir de una enunciación lírica trabajada de manera profunda. Despersonalizado, el poeta veracruzano acude a lo que la mayoría de la crítica de su obra ha denominado máscara o personaje, pero que, en aras de cierta precisión metodológica, es para mí el espacio de enunciación del sujeto lírico. De tal manera que los procedimientos expresivos que distinguen su obra poética, como el tono epigramático con un sarcasmo que en ocasiones se transforma en sátira o humor negro, la desbordante imaginación e ingenio con las palabras y la coloquialidad de situaciones relatadas o dramatizadas, pasan por el tamiz de una enunciación, la cual define y particulariza dichos elementos de su expresión poética.

Para explicar mi comentario analizaré algunos aspectos de "El último verso de Góngora", contenido en Oscura coincidencia (1986). ${ }^{4}$ Este poemario es una obra peculiar por varios motivos: primero, se trata de un libro dividido en cuatro partes distintas sin aparente relación, donde se muestran claramente los principales ejes temáticos del poeta (el amor en sus variantes, sobre todo la carnal, el viaje como imaginación, homenajes y dedicatorias a artistas y el sueño como forma de recuerdo); luego aparece un epígrafe de Bruno Bianco, un nombre de pluma detrás del cual estuvieron Guillermo Fernández y el mismo Hernández en la década de los setenta; finalmente, en este libro se publica el poema "La gata" (también popularmente conocido como Camila, por el nombre del animal) la presencia felina más conocida en la poesía mexicana contemporánea.

${ }^{4}$ Nuevamente ocupo la versión del poema contenida en Antojo de trampa (1999). 
En este libro, al cual no se le ha prestado la atención crítica que merece —quizás en parte porque siempre se prefiere Moneda de tres caras (1994), con la famosa trinidad (Schumann, Scardanelli y Trakl)_, aparece "El último verso de Góngora”, donde se relata un paseo con el poeta rumano Darie Novaceanu en el Parque Hundido de la Ciudad de México. Antes de este poema en prosa, Hernández ya había escrito varios textos sobre asuntos de poesía y poetas o artistas plásticos, como por ejemplo de Lezama Lima, Poe, Picasso y Kafka. Pero es hasta la perspectiva tan clara que el enunciador muestra en su caminata con Novaceanu, como este espacio se convierte en un motivo definido y recurrente en la obra de Hernández. En este proceso se pueden distinguir cuatro instancias progresivas que iré explicando con el poema:

1. El sujeto enunciativo fija una imagen, un cuadro o marco espacial desde donde muestra una perspectiva particular. En el poema se nos presenta como espacio un parque a plena luz del día que se manifiesta bajo la imagen: "y el cielo de estas tierras dejaba caer sobre nosotros su girasol sin polen" (1999: 73). Esta analogía, guarda una proporción con los siguientes elementos descritos que dan cuenta de una interpretación particular del mundo.

2. El enunciador se constituye de acuerdo a su contacto e interpretación con el mundo. El siguiente pasaje: "Una mata de plátano lo entusiasmó como si fuera una columna dórica. Un cerezo encorvado le hizo pensar en cierta esquina de Bucarest" (1999: 72), no hace sino fijar una constitución definitiva del enunciador a partir de las relaciones que establece con el sol, la mata de plátano y un cerezo. Llama la atención la poca o nula relación tangible entre los elementos comparados y, me permito suponer, se trata de una percepción que el sujeto lírico tiene de la poesía del 
rumano. Entonces el enunciador ocupa el espacio del otro y lo interpreta desde la imagen del sol hasta la comparación del platanar con una columna dórica y del cerezo con una esquina. Se hace evidente la dimensión de alteridad que se expresa en el acto poético y que a la mayoría de la crítica de Hernández le gusta denominar el uso de la "máscara"; en esta ocasión el enunciador asume la postura del poeta rumano y con ello un otro.

3. Desde esta situación de alteridad, el enunciador se transforma o presenta una original perspectiva de su entorno, lo cual produce un efecto de sorpresa en el lector que puede traducirse en la experiencia estética del poema. En "El último verso de Góngora”, este efecto queda tan claro cuando el enunciador, bajo el calor de la tarde, nos dice: "Darie se abotonó el cuello de la camisa y me dijo, sacudido por un ligero escalofrío:/ —Basta recordar el último verso de Góngora para que nieve sobre los jardines..." (1999: 73). Se desarrolla una circunstancia absurda que guarda relación con las comparaciones anteriores, pero que no deja de ser sorpresiva para el lector, quien además queda en suspenso a partir de la imprecisión declarativa de Novaceanu. Puede ser que "El último verso de Góngora" aluda a cierto poema a partir de una conversación previa, de la cual el lector no tiene noticias, o bien, literalmente, al último verso escrito por Góngora, lo cual es también enigmático, considerando que su obra se publicó de manera póstuma. El efecto estético de este poema se logra no sólo por la sorpresa de que un verso traiga la nieve en un día soleado y en una ciudad (el Distrito Federal) donde nunca nieva sino también, a partir de la intriga que el poema deja sin resolver, como una emulación al efecto de dificultad poética en algunos poemas de 
Góngora —recordando a Lezama Lima, "sólo lo difícil es estimulante"-.

4. Finalmente, el espacio de enunciación que se presenta en el poema se convierte en un modo de conocimiento de un poeta o un poema $\mathrm{o}$, cuando se trata de un artista plástico, de una impresión de su obra mediante la sensibilidad artística. En términos sencillos diría que la lectura de estos poemas le deja algo al lector que, por la vía del goce estético, se relaciona con un nuevo conocimiento. En este poema, con la estampa sobre Novaceanu caminando por el Parque Hundido, queda vinculado el conocimiento de un poeta rumano y su labor como traductor de Góngora.

Este proceso que acabo de describir ocurre en los otros poemas de la sección "Rostros", de Oscura coincidencia, y será recurrente también en diversos textos a lo largo de la obra del poeta. En 1994 Alberto Paredes dedicó un ensayo a lo que hasta entonces se conocía como la obra poética de Francisco Hernández, fijando sus predilecciones personales. Como proyección vaticinaba lo siguiente:

Una variante prometedora de los recientes poemas cortos de Hernández son aquellos textos de 20 a 40 versos aproximadamente cuyo centro es un personaje. Pienso en "Mirada de Jerez" y en "Palabras por dos hombres". En ambos casos el éxito estriba en que el poema construya una identidad lírica (1994: 108).

Este tipo de textos, además de volverse favoritos, se particularizaron de tal manera hasta convertirse en una forma discursiva personal, las poetografías. El recurso, en sí, incluso se ha convertido en parte del método de un taller de escritura creativa.

En una breve nota sobre la poesía de Francisco Hernández, Víctor Manuel Mendiola distingue "dos segmentos: aquellos poemas donde el autor mira el mundo sin la mediación de otras voces 
interpuestas y aquellos otros donde encontramos la elaboración o la reelaboración de un personaje” (2001: 113). Yo más bien creo que aun cuando no median "voces interpuestas", sí existe un sujeto enunciativo propio de la lírica, lo cual provoca la despersonalización del poeta que he descrito líneas arriba. Así visto, el lector se entusiasma con los poemas de Hernández porque se instala en un espacio de enunciación poco frecuentado por la poesía mexicana contemporánea.

Este sujeto lírico involucra al lector en un acto de reconocimiento de sí mismo a partir de lo que se enuncia. La sensación de que Francisco Hernández es sencillo, cotidiano y comprensible en su poesía, se logra porque ha sido capaz de desprenderse de las emociones personales para mediarlas a través de un sujeto enunciativo lírico que nos hace confluir en un mismo tiempo y espacio.

$\mathrm{El}$ artificio que varios críticos y lectores de este importante poeta han denominado "personaje" o "máscara” es, de manera más precisa, un sujeto enunciativo de la lírica. Estudiarlo con detalle nos permitirá conocer la profunda complejidad que subyace en la poesía de Francisco Hernández y entender su riqueza discursiva. Esto habrá de ser definitorio para que, además de ser un poeta de culto que circula entre las aulas de letras como uno de los secretos mejores guardados de la poesía mexicana, se convierta en una figura medular de nuestra literatura.

\section{Bibliografía}

Aristóteles, 1974, Poética, Valentín García Yebra (trad.), edición trilingüe, Madrid, Gredos.

Ballart, Pere, 2005, El contorno del poema, Barcelona, Acantilado.

Benveniste, Emile, 1993, Problemas de lingüistica general, 2 vols., México, Siglo XXI editores. 
Borges, Jorge Luis, 1999, "Borges y yo", en Borges por él mismo, Madrid, Visor, pp. 22-23.

Espinasa, José Ma., abril de 2005, "Poeta ventrílocuo. Reseña a El corazón y su avispero e Imán para fantasmas de Francisco Hernández", en Letras libres, México, pp. 75-76.

Greimas, Algirdas Julien et al., 1976, Ensayos de semiótica poética, Barcelona, Planeta.

Hamburger, Käte, 1995, La lógica de la literatura, Madrid, Visor.

Hernández, Francisco, 2013, Moneda de tres caras, $3^{\mathrm{a}}$ ed., Monterrey, Universidad Autónoma de Nuevo León.

, 1999, Antojo de trampa. Segunda antología personal, México, FCE.

Hernández Palacios, Esther y Ángel José Hernández, 1992, Veracruz, dos siglos de poesía (XIX y XX), 2 t., México, Conaculta.

Lezama Lima, José, 1993, La expresión americana, Irlemar Champi (ed.), México, FCE.

Mendiola, Víctor Manuel, 2001, Sin cera, México, UNAM, pp. 113-115.

Paredes, Alberto, 1994, "Los viajes del silencio o la locura del héroe", Tema y variaciones de literatura. El viaje, núm. 3, UAMAzcapotzalco, México, disponible en: <http://espartaco.azc. uam.mx/UAM/TyV/3/221063/221063.html> (consultado el: 3/VI/2013).

Pozuelo Yvancos, José María, 1998, “Enunciación lírica?”, en Teoría del poema: la enunciación lírica, Cabo Aseguinolaza, Fernando y Germán Gullón (eds.), Ámsterdam, Rodopi, Diálogos hispánicos, núm. 21, pp. 41-75. 
Rabaté, Dominique, 1996, Figures du sujet lyrique, Francia, Presses universitaires de France.

Sinta, Mardonio, 2007, ¿Quién me quita lo cantado?, México, UNAM.

Todorov, Tzvetan, 1970, "Problèmes de l'énonciation", Langages, año 5, núm. 17, pp. 3-11.

(Recibido: 23 de enero de 2015, aceptado: 15 de febrero de 2015) 